\title{
El papel de la cosmética: excipientes y conservantes
}

\author{
M. Madurga Sanz \\ Farmacéutico y Farmacoepidemiólogo. Agencia Española de Medicamentos y Productos Sanitarios (AEMPS). \\ Ministerio de Sanidad y Consumo. Madrid.
}

Rev Pediatr Aten Primaria. 2009; I Supl I5: s8I-s 100

Mariano Madurga Sanz, mmadurga@agemed.es

\section{Resumen}

En este artículo se expone el marco normativo que se aplica a los cosméticos, según la normativa española en el marco europeo de armonización. En particular se exponen los criterios de utilización de los excipientes de estos productos manufacturados, en concreto de los colorantes y conservantes. Estos pueden ser factores de riesgo de las reagudizaciones de dermatitis atópica (DA), debido a su poder alergizante. La vigilancia de los efectos adversos de los cosméticos (cosmetovigilancia) debe ser una actividad con mayor implantación.

Palabras clave: Dermatitis atópica, Cosméticos, Colorantes, Conservantes, Cosmetovigilancia.

\section{Abstract}

En este artículo se expone el marco normativo que se aplica a los cosméticos, según la normativa española en el marco europeo de armonización. En particular se exponen los criterios de utilización de los excipientes de estos productos manufacturados, en concreto de los colorantes y conservantes. Estos pueden ser factores de riesgo de las reagudizaciones de dermatitis atópica (DA), debido a su poder alergizante. La vigilancia de los efectos adversos de los cosméticos (cosmetovigilancia) debe ser una actividad con mayor implantación.

Key words: Atopic dermatitis, Cosmetics, Colouring, Preservatives, Cosmetovigilance.

\section{Introducción}

La prevalencia de la dermatitis atópica (DA) en la edad pediátrica alcanza cifras del $15-20 \%$. En su tratamiento sintomático son tan importantes las terapias farmacológicas como evitar el contacto con sustancias irritantes. La paradoja actual es que algunos de los productos cosméticos son causa de dermatitis alérgicas. Por lo tanto, la situación es compleja si contemplamos los datos que constatan una incidencia de efectos adversos asociados al uso de cosméticos, con una gran infranotificación. Como el Consejo de Europa 
reflejó en su informe ${ }^{1}$ de 2006, con los resultados de un estudio piloto llevado a cabo en 2004-2005, sobre la vigilancia de los efectos indeseables de los cosméticos: solo el $25-36 \%$ de las personas comunicaron a su médico el hecho de que habían experimentado algún efecto indeseable durante el uso de cosméticos, siendo muy significativa esta infranotificación dado que el $15 \%$ de los casos fueron graves. Entre las reacciones ad- versas notificadas, las dermatitis alérgicas de contacto fueron las más frecuentemente notificadas $(76,5-83,9 \%)$. El estudio constató que los productos para el cuidado de la cara, los tintes capilares y los preparados capilares fueron los grupos de productos que fueron causa más frecuente de las dermatitis. Entre los alergenos, los más frecuentes fueron los aromas, los conservantes y los tintes capilares. Las conclusiones y propuestas del

Tabla I. Categorías de productos cosméticos (RD 1599/1997 y modificaciones)2

- Cremas, emulsiones, lociones, geles y aceites para la piel.

- Máscaras de belleza (con exclusión de los productos de abrasión superficial de la piel por vía química).

- Maquillaje (líquidos, pastas, polvos).

- Polvos de maquillaje, polvos para utilizar después del baño y para la higiene corporal.

- Jabón de tocador, jabón desodorante.

- Perfumes, aguas de tocador, aguas de colonia.

- Productos capilares:

- Tintes y decolorantes.

- Productos para moldear, para desrizar y fijar.

- Productos que ayudan a mantener el peinado.

- Productos de limpieza (lociones, polvos, champús).

- Productos acondicionadores (lociones, lacas, brillantinas).

- Otros productos para el peinado.

- Productos para el afeitado (jabones, espumas, lociones).

- Productos para el maquillaje y desmaquillaje de la cara y los ojos.

- Productos para los labios.

- Productos para el cuidado bucal y dental.

- Productos para el cuidado y maquillaje de las uñas.

- Productos para el cuidado íntimo externo.

- Productos solares.

- Productos para el bronceado sin sol.

- Productos blanqueadores de la piel.

- Productos antiarrugas.

- Productos para baño y ducha (sales, espumas, aceites, geles).

- Depilatorios.

- Desodorantes y antitranspirantes. 
citado informe, suscrito por el Comité de Ministros, son claras: en Europa deben ponerse en marcha sistemas de vigilancia de los efectos indeseables asociados al uso de los cosméticos, con el fin de proteger la salud pública de nuestras poblaciones.

\section{Cómo se define un cosmético}

Los cosméticos se definen como "toda sustancia o preparado destinado a ser puesto en contacto con las diversas partes superficiales del cuerpo humano (epidermis, sistema piloso y capilar, uñas, labios y órganos genitales externos) o con los dientes y las mucosas bucales, con el fin exclusivo o principal de limpiarlos, perfumarlos, modificar su aspecto, y/o corregir los olores corporales, y/o protegerlos o mantenerlos en buen estado" (Real Decreto [RD] 1599/1997 y posteriores modificaciones ${ }^{2}$ ). A título indicativo, en la tabla I se muestran los tipos existentes de cosméticos.
También existe una categoría específica denominada cosméticos decorativos, como "los que, en virtud de poseer sustancias coloreadas y por su poder cubriente, se aplican sobre diferentes zonas del cuerpo, con el fin de acentuar temporalmente su belleza o enmascarar o disimular diversas imperfecciones $\mathrm{Cu}$ táneas" (RD 1599/1997 y modificaciones ${ }^{2}$ ). A nivel indicativo se consideran cosméticos decorativos los que se reúnen en la tabla II. Como se puede apreciar, generalmente son de aplicación en personas adultas.

Pero no son todos. También se definen, como grupo adicional, los llamados productos de higiene personal, como "aquellas sustancias o preparados que, sin tener la consideración legal de cosméticos, biocidas, productos sanitarios o medicamentos, están destinados a ser aplicados sobre la piel, dientes o mucosas del cuerpo humano con la finalidad de higiene o de estética, o para neutrali-

Tabla II. Categorías de productos cosméticos decorativos (RD 1599/1997 y modificaciones)2

- Maquillaje de labios

- Sombra de párpados

- Colorete

- Lápiz de ojos

- Maquillaje de fluido

- Maquillaje en polvo

- Máscara de pestañas

- Esmalte de uñas 
zar o eliminar ectoparásitos, tales como dentífricos, productos de estética, pediculicidas, hidratantes vaginales, limpiadores anales en caso de hemorroides, productos para el masaje deportivo, limpiadores nasales o limpiadores oculares, o cualquier otro producto que pueda ser calificado como tal". Algunos de estos se definen así:

- Dentífricos: las sustancias o preparados que se aplican en la mucosa bucal y/o en los dientes que, por sus indicaciones, composición o forma de presentación, no pueden ser considerados cosméticos, tales como pastas dentífricas, colutorios, blanqueantes dentales, chicles o comprimidos para higiene bucal o productos hiperfluorados de uso profesional o cualquier otro producto que pueda ser calificado como tal.

- Productos de estética: los productos de aplicación en la piel, que no tengan la consideración legal de cosméticos, medicamentos o productos sanitarios por su composición, indicaciones, mecanismo de acción, de aplicación o duración, tales como, en su caso, tintas para tatuajes, micropigmentos o preparados destinados al maquillaje permanente $y$ semipermanente, mascarillas de abrasión de la piel por vía química o parches transdérmicos, o cualquier otro producto que pueda ser calificado como tal.

Pero también existen exclusiones. En la normativa en vigor (artículo 3 del RD 1599/1997 y modificaciones²) se citan como productos excluidos en esta reglamentación "aquellos preparados destinados a la prevención, diagnóstico y tratamiento de enfermedades, así como los destinados a ser ingeridos, inhalados, inyectados o implantados en el cuerpo humano. Tampoco se consideran cosméticos aquellos preparados destinados a la protección frente a la contaminación o infección por microorganismos, hongos o parásitos".

Para todo este conjunto de productos existe su reglamentación pertinente. Desde diferentes momentos de partida, en la Unión Europea (UE) se ha consolidado una reglamentación técnico-sanitaria que se aplica a todos estos productos. Desde 1988 se armonizan en España las normativas correspondientes y con la promulgación del RD 1599/1997 se sentaron las bases de esta armonización con las directivas europeas, en concreto la Directiva 93/35/CEE (que modificaba la anterior Directiva 76/768/CEE, denominada Directiva Europea Cosmética) que estableció el marco regulador para los cosméticos. Posteriores directivas y sus 
correspondientes reales decretos que han modificado 2 sucesivamente el RD 1599/1997, ofrecen un marco normativo que combina las exigencias actuales. Entre los aspectos novedosos que se han introducido en los decretos de finales de los años 90 cabe señalar la información que deben facilitar los responsables de la puesta en el mercado a las autoridades sanitarias a efectos de un tratamiento médico rápido y adecuado en caso de problemas; la obligación de reflejar en el etiquetado los ingredientes que se emplean en el producto cosmético; la memoria técnica que deben elaborar las empresas y mantener a disposición de las autoridades sanitarias; y la prohibición, a partir del 30 de junio de 2000, de poner en el mercado productos cosméticos que contengan ingredientes o combinaciones de ingredientes que se hayan experimentado en animales. Destaca también la posibilidad para los fabricantes de solicitar la exclusión de uno o varios de los ingredientes del etiquetado de los productos cosméticos, por razones de confidencialidad comercial.

\section{Obligaciones del responsable de comercialización}

La reglamentación actual sobre productos cosméticos establece que los productos cosméticos que se comercia- licen en el territorio comunitario de la UE, no deberán perjudicar la salud humana cuando se apliquen en las condiciones normales o previsibles de uso teniendo en cuenta entre otras, la información en las instrucciones de uso. Los riesgos que pudieran previsiblemente derivarse de la normal utilización de los productos cosméticos, teniendo en cuenta su naturaleza y las personas a las que van destinados, deberán ser puestos en conocimiento previo de los consumidores, por medio de instrucciones e indicaciones para su uso correcto y de advertencias apropiadas.

Todo esto en el marco de las exigencias de la normativa actualmente en vigor $^{2}$, que establece como obligación del fabricante o del responsable de la puesta en el mercado de los productos cosméticos lo siguiente: tanto el fabricante si es español, como el responsable de la puesta en el mercado si se fabrica en la Unión Europea, deben enviar a la Agencia Española de Medicamentos y Productos Sanitarios (AEMPS) y a la comunidad autónoma correspondiente a su ubicación, si está en España, no más tarde del día en que se haga efectiva la puesta en el mercado del cosmético en España, la información recogida ${ }^{2}$ en el artículo 8 del RD 1599/1997, según el anexo II. Para el caso de cosméticos fa- 
bricados fuera de la Unión Europea, el importador debe tener una autorización previa otorgada por la AEMPS, en la que el importador demuestre que el almacenamiento y control de los productos cosméticos se realizan de forma adecuada.

\section{Información a efectos de tratamiento médico (IETM)}

En las tres situaciones contempladas anteriormente, el responsable debe enviar a la AEMPS, y en su caso a la comunidad autónoma correspondiente, la denominada "información a efectos de tratamiento médico" (IETM), que se describe en el artículo 8 del citado RD ${ }^{2}$ (tabla III). Estos datos se introducirán en un sobre cerrado que, junto con un escrito de remisión, se dirigirá a la AEMPS. Actualmente, en la Subdirección General de Productos Sanitarios, de la AEMPS, se dispone de una base de datos de cosméticos, con acceso autoriza- do, entre otras instituciones, a cada responsable de la puesta en el mercado del producto cosmético para remitir información y sus actualizaciones en cuanto a la documentación requerida.

Los datos de la IETM son trascendentales cuando se necesite bajo criterio médico para atender un incidente o una reacción adversa, posiblemente asociada al uso del producto cosmético. Por esta razón, el Servicio de Información Toxicológica (SIT) del Instituto Nacional de Toxicología y Ciencias Forenses, del Ministerio de Justicia, tiene acceso a esta fuente de información para poder atender las consultas. A través de su SIT³ (teléfono 9156204 20, las 24 horas del día, los 365 días del año), recibe y responde consultas sobre todo tipo de intoxicaciones incluidas las ocasionadas por cosméticos. Este servicio del SIT se cita, asimismo, en los prospectos de los medicamentos autorizados y comercializados en España. La

Tabla III. Información a efectos de tratamiento médico (IETM) que se debe facilitar a la AEMPS

- Denominación del producto (deberá incluirse la marca y el nombre específico del producto).

- Composición cuantitativa: se relacionarán todos los ingredientes en orden decreciente de concentración de acuerdo con la Nomenclatura Internacional de Ingredientes Cosméticos (INCI), publicada en el Inventario de Ingredientes (en la página web de la AEMPS: www.agemed.es/actividad/pschb/docs/ inventario_cosmet-junio06.pdf).

- Constantes físicoquímicas que puedan ser relevantes a efectos de tratamiento médico y descripción del producto.

- Prospectos y en caso de que no existieran o no aparecieran en el mismo, las menciones exigidas en el artículo 15-Etiquetado del recipiente y embalaje. 
propia AEMPS ofrece un acceso por correo electrónico (cosmetvigil@agemed. es) para poder recibir información, consultas, notificaciones o comunicaciones de efectos adversos relacionados con el uso de productos cosméticos o de higiene, que le remitan los profesionales de la salud.

\section{Etiquetado ¿qué información tiene que contener?}

Según el artículo 15 del RD 1599/ 1997 y modificaciones ${ }^{2}$, el etiquetado es el texto impreso, adherido al recipiente o al embalaje o bien colgante de ellos, conteniendo información y datos preceptivos del producto. Esta información es la siguiente:

a) Denominación del producto.

b) El nombre o la razón social y la dirección o el domicilio social del fabricante, o del responsable de la puesta en el mercado del producto establecido dentro del territorio comunitario. Estas menciones podrán abreviarse siempre y cuando su abreviatura permita, en términos generales, identificar a la empresa.

c) El contenido nominal en el momento del acondicionamiento, indicado en peso o en volumen, salvo para los envases que contengan menos de $5 \mathrm{~g}$ o menos de $5 \mathrm{ml}$, las muestras gratuitas y las dosis únicas; respecto a los productos preenvasados, que se comercializan habitualmente por conjuntos de unidades y para los que no es significativa la indicación del peso o del volumen, no será necesario indicar el contenido, siempre que se mencione en el envase el número de piezas. Esta mención no será necesaria cuando sea fácil determinar desde el exterior el número de piezas o si el producto solo se comercializa normalmente por unidades sueltas (ver Símbolos del etiquetado).

d) La fecha de caducidad mínima (FCM): la FCM de un producto cosmético es la fecha hasta la cual dicho producto, conservado en condiciones adecuadas, continúa cumpliendo su función inicial y, en particular, sigue cumpliendo las exigencias previstas en el artículo 4.1 del RD². La FCM se indicará mediante la mención "utilícese preferentemente antes de final de...", indicándose a continuación: o bien la propia fecha, o bien la indicación del lugar del etiquetado donde figura. En caso de necesidad, estas menciones se completarán con la indicación de las condiciones que permitan garantizar la duración indicada. La FCM se compondrá de la indicación, de forma clara y ordenada, del mes y del año. Para los productos cosméticos cuya vida mínima exceda de 30 meses, la indicación de la fecha de caducidad no será 
obligatoria. Para estos productos se indicará el plazo después de su apertura durante el cual pueden utilizarse sin ningún riesgo para el consumidor. Esta información se indicará mediante el símbolo previsto en el anexo VIII bis del RD², seguido del plazo en meses y/o años (ver figura 1 y Símbolos del etiquetado).

e) Las precauciones particulares de empleo y especialmente las indicadas en la columna "Condiciones de empleo y advertencias que deben figurar obligatoriamente en el etiquetado", de los anexos III, IV, VI y VII del RD² que deben figurar en el recipiente y embalaje, así como eventuales indicaciones relativas a las precauciones particulares que deban observarse con los productos cosméticos de uso profesional, en particular los destinados a los peluqueros. Cuando esto no fuera posible en la práctica, estas indicaciones habrán de consignarse en una nota, una etiqueta, una banda o una tarjeta adjuntas, a las cuales se remitirá al consumidor, bien mediante una indicación abreviada o bien por el símbolo del anexo VIII del $\mathrm{RD} 2$, que deberá figurar en el recipiente $y$ en el embalaje.

f) El número de lote de fabricación o la referencia que permita la identificación de la fabricación. Cuando esto no fuera posible en la práctica, debido a las reducidas dimensiones de los productos cosméticos, esta mención solo deberá figurar en el embalaje.
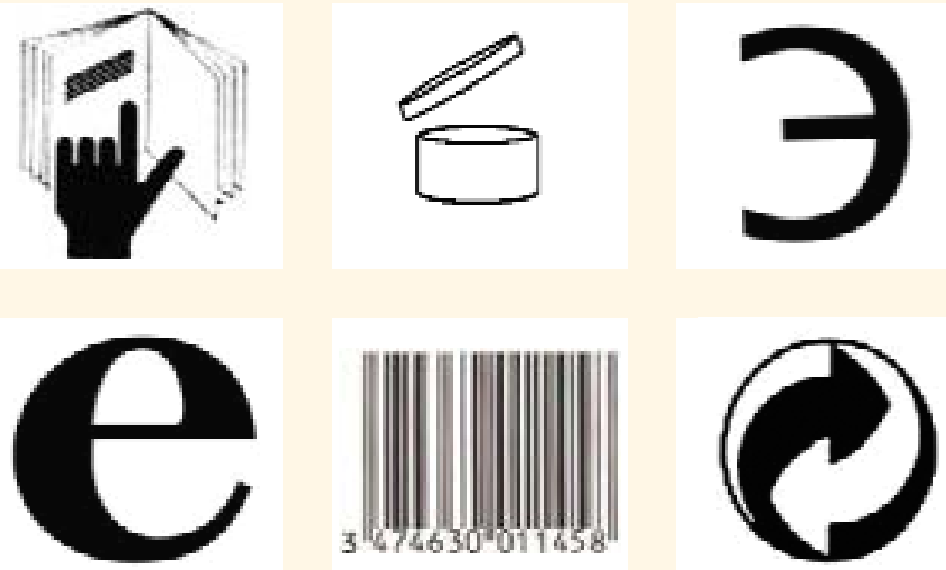
g) País de origen cuando se trate de productos cosméticos fabricados fuera del territorio comunitario.

h) La función del producto, salvo si se desprende de su presentación.

i) La lista de ingredientes por orden decreciente de importancia ponderal en el momento de su incorporación. Esta lista irá precedida de la palabra "ingredientes" o "ingredients". En caso de que fuera imposible en la práctica, los ingredientes figurarán en una nota, una etiqueta, una banda o una tarjeta adjuntas, a las cuales se remitirá al consumidor, bien mediante una indicación abreviada, bien por el símbolo del anexo VIII que deberán figurar en el embalaje.

Los compuestos perfumantes y aromáticos, así como sus materias primas, se mencionarán con la palabra "perfume" o "parfum" y "aroma", respectivamente. No obstante, la presencia de sustancias cuya mención es obligatoria en la columna "Otras limitaciones y exigencias" del anexo III del RD² se indicarán en la lista independientemente de su función en el producto.

Los ingredientes de concentración inferior al $1 \%$ podrán mencionarse sin orden después de los que tengan una concentración superior a dicho porcentaje. Los colorantes podrán mencionar- se sin orden después de los demás ingredientes, mediante el número del "Colour Index" o de la denominación que figura en el anexo IV.

Para los productos cosméticos decorativos comercializados con diferentes matices de colores, podrá mencionarse el conjunto de los colorantes utilizados en la gama, siempre que se añadan las palabras "puede contener" o el símbolo "+/-".

El fabricante podrá solicitar, por razones de confidencialidad comercial, la exclusión de uno o de varios ingredientes de dicha lista, de acuerdo con lo establecido en el artículo 17 (confidencialidad de ingredientes), del RD², por el que se autorizará, sin perjuicio de la protección de la salud pública, y siempre por un máximo de 5 años iniciales al uso de ese ingrediente.

\section{Símbolos del etiquetado}

Si observamos la etiqueta de cualquier envase, encontramos símbolos cuyo significado es, en ocasiones, desconocido. Los más habituales son los siguientes (ver figura 1):

- Mano sobre libro. Cuando aparece en el embalaje remite al consumidor al listado de ingredientes, que figurará en una etiqueta, una nota, una banda o una tarjeta adjuntas. Se 
emplea cuando no es posible que los ingredientes figuren en el embalaje (p. ej., por su pequeño tamaño). Se describe en el anexo VIII del RD 1599/1997².

- Plazo de caducidad una vez abierto.

Para los productos cosméticos cuya vida mínima exceda de 30 meses, la indicación de la fecha de caducidad no será obligatoria. Para estos productos se indicará el plazo después de su apertura, durante el cual pueden utilizarse sin ningún riesgo para el consumidor. Este es el símbolo previsto en el anexo VIII bis, seguido del plazo en meses y/o años, por ejemplo "12M".

- Letra épsilon invertida. Aparece en los aerosoles, como indicación del contenido. Es acreditativa de que el producto cumple con las legislaciones relacionadas con aerosoles.

- Contenido efectivo. Es un símbolo obligatorio solo y exclusivamente para los productos alimenticios envasados, por lo que su uso en cosmética es facultativo, indicando el contenido del envase, por ejemplo $200 \mathrm{ml}$ o 400 $\mathrm{ml}$. El símbolo "debe ir colocado junto a la indicación de la cantidad nominal, con una altura mínima de $3 \mathrm{~mm}$ y con la forma y dimensiones representadas en el RD 723/1988".
- Código de barras. De utilización voluntaria, no está regulado por ninguna legislación, ni europea ni española. Aparecerá en la parte externa de cada unidad de venta.

- Punto Verde. Indica que la empresa responsable de ese envase se encuentra adherida a un sistema integrado de gestión (SIGRE) de residuos de envases y envases usados. Es un símbolo en dos colores, verde oscuro y verde claro, con un tamaño aconsejado de $10 \mathrm{~mm}$ de diámetro, que aparece en el embalaje exterior 0 , si no es posible, en el propio recipiente.

\section{Ingredientes y excipientes:}

colorantes, conservantes

En la composición de los productos cosméticos entran a formar parte una diversidad de sustancias de origen químico, mineral, vegetal o animal. Estas sustancias 0 ingredientes que pueden formar parte de un producto cosmético están incluidas en una lista, permanente actualizada en el ámbito europeo. En la lista actual, estos ingredientes se clasifican en grupos diferentes según su actividad. Algunos de estos grupos se describen en la tabla IV. Unos son incorporados por sus efectos cosméticos y otros con un objetivo de complemento para el resto de com- 
Tabla IV. Ejemplos de categorías de ingredientes que forman parte de los productos cosméticos ${ }^{4}$

- Absorbente. Recoge (empapa) agua y/o sustancias liposolubles disueltas o finamente dispersadas.

- Acondicionador de uñas. Mejora las características cosméticas de las uñas.

- Acrecentador de espuma. Aumenta la calidad de la espuma producida por un determinado sistema, incrementando una o más de las siguientes propiedades: volumen, textura y/o estabilidad.

- Aglutinantes. Proporcionan cohesión a los cosméticos.

- Antiagregante. Permite el libre flujo de partículas sólidas y así evita la aglomeración de los cosméticos en polvo en grumos o masas endurecidas.

- Anticaspa. Ayuda a controlar la caspa.

- Anticorrosivo. Previene la corrosión de los envases.

- Antiespumante. Suprime la espuma durante el proceso de fabricación o reduce la tendencia de los productos terminados a producir espuma.

- Antiestático. Reduce la electricidad estática, neutralizando la carga eléctrica superficial.

- Antimicrobiano. Ayuda a controlar el crecimiento de microorganismos en la piel.

- Antioxidante. Inhibe las reacciones provocadas por el oxígeno, evitando de esta forma la oxidación y el enranciamiento.

- Antiplaca. Ayuda a proteger contra la placa dental.

- Antiseborreico. Ayuda a controlar la producción de sebo.

- Antitranspirante. Reduce la transpiración.

- Astringente. Contrae la piel.

- Blanqueante. Aclara el tono del cabello o la piel.

- Bronceador. Oscurece la piel con o sin exposición a lo rayos UV.

- Colorante cosmético. Colorea el producto cosmético y/o da color a la piel y/o sus apéndices. Todos los colorantes listados son sustancias incluidas en la lista positiva de colorantes (anexo IV de la Directiva de cosméticos).

- Conservantes. Inhibe primariamente el desarrollo de microorganismos en los cosméticos. Todos los conservantes listados son sustancias en la lista positiva de conservantes (anexo VI de la Directiva de cosméticos).

- Controladores de viscosidad. Aumentan o disminuyen la viscosidad de los cosméticos.

- Cuidado oral. Proveer de efectos cosméticos a la cavidad oral, por ejemplo, limpieza, desodorización, protección.

- Emoliente. Alisa y suaviza la piel.

- Filtro UV. Filtra ciertas radiaciones UV con el fin de proteger la piel o el cabello de los efectos perjudiciales de esta radiación. Todos los filtros listados son sustancias en la lista positiva de filtros solares (anexo VII de la Directiva de cosméticos).

- Hidrótropo. Intensifica la solubilidad de una sustancia que es solo ligeramente soluble en agua.

- Humectante. Mantiene y retiene la humedad.

- Limpiador. Ayuda a mantener limpia la superficie del cuerpo.

- Nacarante. Da un aspecto nacarado a los cosméticos.

- Opacificante. Reduce la transparencia o traslucidez de los cosméticos.

- Oxidante. Cambia la naturaleza química de otra sustancia, añadiendo oxígeno o eliminando hidrógeno.

- Propelente. Genera presión en un envase aerosol, expeliendo el contenido cuando se abre la válvula. Algunos propelentes líquidos pueden actuar como disolventes.

- Quelante. Reacciona y forma complejos con los iones metálicos que podrían afectar la estabilidad y/o el aspecto de los cosméticos.

- Queratolítico. Ayuda a eliminar las células muertas del estrato córneo.

- Tamponante. Estabiliza el pH de los cosméticos.

- Voluminador. Controla la densidad del cosmético terminado. 
ponentes a los que estabilizan, preservan, aglutinan, etc., y por lo tanto podíamos decir que son excipientes, tal como se incorporan en los medicamentos.

Tal como se señala en la tabla IV, los conservantes y los colorantes cosméticos deben estar incluidos en listas positivas que se adjuntan en anexos a la normativa citada² (RD 1599/1997). En conjunto, se manejan las listas positivas siguientes:

- Lista acumulada ${ }^{4}$ de todos los ingredientes permitidos en los productos cosméticos. (Se puede consultar en la página de Internet de la AEMPS: www.agemed.es/actividad/pschb/ docs/inventario_cosmet-junio06. pdf).

- Lista de colorantes que pueden contener los productos cosméticos (anexo IV, primera parte).

- Lista de colorantes admitidos provisionalmente que pueden contener los productos cosméticos (anexo IV, segunda parte).

- Lista de agentes conservadores que pueden contener los productos cosméticos (anexo $\mathrm{VI}$, primera parte con 56 agentes).

- Lista de filtros UV que pueden contener los productos cosméticos (anexo VII, con 20 filtros diferentes).
A estas listas positivas, acompañan dos listas más, que son negativas o restrictivas. La lista restrictiva de ingredientes en ciertas condiciones (corresponde al anexo III), unas admitidas provisionalmente (segunda parte, con unas 60 sustancias) y otras identificadas con restricciones (anexo III, primera parte, con 101 sustancias) del tipo de los siguientes:

- Talco (silicato de magnesio hidratado), en cosméticos para niños menores de 3 años: "mantener apartado de la nariz y de la boca del niño". - Ácido bórico, boratos y tetraboratos, en talcos al $5 \%$ máximo expresado en ácido bórico, con leyenda en el etiquetado: "no utilizar en niños menores de 3 años".

- Tetraboratos en productos para el baño, al 18\% máximo expresado en ácido bórico, con la leyenda en el etiquetado: "no utilizar para el baño de niños menores de 2 años".

La lista de sustancias prohibidas en la composición de los productos cosméticos (corresponde al anexo II, con unas 1.328 sustancias, a fecha de marzo de 2008) se actualiza permanentemente. Este es el motivo de la retirada de productos cosméticos que fraudulentamente incorporan sustancias no permitidas. Recientemente, la AEMPS ha difundido la nota informativa ${ }^{5}$ sobre un 
producto cosmético, "Mene \& Moy Yellow Peel", ordenando la prohibición de su comercialización y retirada del mercado a cargo de la empresa (Mediform Productos y Servicios Médicos, S.L.) debido a que contenía ácido retinoico en concentración del $5 \%$. Este retinoide es un ingrediente prohibido en los productos cosméticos, e incluido con el número 379, en el anexo II del RD 1599/ 1997, si bien se utiliza como principio activo en medicamentos autorizados a concentraciones inferiores al 0,5\%. Como se ha comentando anteriormente, el citado $\mathrm{RD}^{2}$ prohíbe la puesta en el mercado de productos cosméticos que contengan sustancias comprendidas en el anexoll.

En 2006, otro ejemplo de control administrativo fue la prohibición de comercialización y retirada del mercado del producto "CNA Crema", comercializado por Lou Cosmética Aplicada. La medida ${ }^{6}$ se adoptó al haberse detectado la presencia de 0,12 $\mathrm{mg} / \mathrm{g}$ de betametasona dipropionato. La betametasona dipropionato es una sustancia que pertenece al grupo de los glucocorticoides, ingredientes prohibidos en productos cosméticos e incluidos, con el número 300 , en el anexo II citado. Son ejemplos de que en el caso de que se incumplan las regulaciones, las Administraciones públicas sanitarias vigilan y tutelan la seguridad de los productos cosméticos, con la colaboración de todos los agentes, instituciones, profesionales y, cada día más, con los ciudadanos.

Por lo tanto, podemos resumir que queda prohibida la puesta en el mercado de los productos cosméticos que contengan:

a) Las sustancias comprendidas en el anexo II del RD 1544/1997.

b) Las sustancias comprendidas en el anexo III, en concentraciones superiores y en condiciones diferentes de las establecidas en dicho anexo.

c) Colorantes no incluidos en el anexo IV con excepción de los productos cosméticos que contengan colorantes destinados únicamente a teñir el sistema piloso.

d) Colorantes comprendidos en el anexo IV, en concentraciones superiores y en condiciones diferentes a las establecidas, con excepción de los productos cosméticos que contengan colorantes destinados únicamente a teñir el sistema piloso.

e) Agentes conservadores no incluidos en el anexo VI.

f) Agentes conservadores comprendidos en el anexo VI en concentraciones superiores y en condiciones diferentes de las establecidas en dicho anexo. 
g) Filtros ultravioleta no incluidos en el anexo VII.

h) Filtros ultravioleta comprendidos en el anexo VII en concentraciones superiores y en condiciones diferentes de las establecidas en dicho anexo.

La lista de los 56 agentes conservadores permitidos en los productos cosméticos (corresponde al anexo VI del RD 1599/1997 y sus modificaciones ${ }^{2}$ : www. agemed.es/actividad/pschb/docs/cos meticos_anexolV-X-enero06.pdf) se incorporan para inhibir el desarrollo de microorganismos en los cosméticos. En todos los casos se limita su cantidad a niveles porcentuales, aunque en algunos casos pueden incorporarse en cantidades superiores con otros fines como desodorante en jabones 0 agentes anticaspa en los champús. Por ejemplo, el ácido salicílico se puede utilizar por encima del $0,5 \%$, pero en cualquier caso no está permitido su uso en niños menores de 3 años, tal como se debe indicar en el etiquetado en estos casos. También hay que recordar que otras sustancias empleadas pueden tener, además, propiedades antimicrobianas y de esta manera pueden contribuir a la conservación de los productos, como por ejemplo ciertos aceites esenciales y algunos alcoholes, pero sin listar entre las sustancias conservantes.
En general, los conservantes pueden ser sales de cationes de sodio, potasio, magnesio, calcio, amonio y etanolaminas; y de aniones cloruro, bromuro, sulfato y acetato. También pueden ser ésteres de metilo, etilo, propilo, isopropilo, butilo, isobutilo y fenilo. En los productos que contienen el conservante formaldehído (formol o formalina), o sustancias que liberen formaldehído, debe figurar obligatoriamente en el etiquetado la mención "contiene formaldehído", siempre que la concentración de formaldehído en el producto cosmético terminado sobrepase $0,05 \%$. También debe indicarse en el etiquetado condiciones de empleo y advertencias en el caso de otros conservantes, como:

- Ácido salićlico (máximo 0,5\%): “No emplear para cuidados de niños menores de 3 años".

- Clorobutanol (máximo 0,5\%): "Contiene clorobutanol".

- Tiomersal (máximo 0,007\% en Hg): "Contiene tiosalicilato de etilmercurio sódico (tiomersal)".

- Fenilmercurio y sus sales (máximo 0,007\% en $\mathrm{Hg}$ ): "Contiene compuestos fenilmercúricos".

- Cloracetamida (máximo 0,3\%): "Contiene cloracetamida".

- Glutaraldehído (máximo 0,1\%): 
"Contiene glutaraldehído" (cuando la concentración de glutaraldehído en el producto acabado sobrepase el $0,05 \%$ ).

- Benzalconio cloruro, bromuro o sacarinato (máximo 0,1\% expresado en cloruro de benzalconio): "Evitar el contacto con los ojos".

Todos los ingredientes cosméticos tienen una denominación oficial según la nomenclatura $\mathrm{INCl}$ (International Nomenclature of Cosmetic Ingredients) -antes, CTFA- desarrollada conjuntamente por las industrias cosméticas de EE. UU. y la UE, que es la utilizada para tal fin. Los nombres INCI de las sustancias cosméticas se publican en un inventario $^{4}$ de la UE que se actualiza periódicamente. También pueden tener Denominación Común Internacional (DCl) o INN (Internacional Non-propietary Name) otorgada por la OMS, así como la denominación FE (Farmacopea Europea), número CAS (Chemical Abstracts), el número EINECS/ELINCS en el Catálogo Europeo de Sustancias Químicas Comercializadas (European inventory of existing commercial chemical substances, EINECS) para sustancias químicas existentes o en la Lista Europea de Sustancias Químicas Notificadas (European List of Notified Chemical Substances, ELINCS) y, por último, su denominación de la IUPAC, que abarca la denominación química y la denominación de la Unión Internacional de Química Pura y Aplicada (International Union of Pure and Applied Chemistry, IUPAC). Se pueden identificar las diferentes denominaciones en el inventario citado ${ }^{4}$ anteriormente de ingredientes permitidos empleados en los productos cosméticos.

Pero en el caso particular de los colorantes que pueden contener los cosméticos se añade una denominación numérica, a continuación de su acrónimo $\mathrm{Cl}$ (Colour Index), tal como se encuentran en los listados en el anexo IV del RD 1544/1997 (www.agemed.es/acti $\mathrm{vidad} / \mathrm{pschb} /$ docs/cosmeticos_anexo IV-X-enero06.pdf). Además, en algunos casos tienen código español, que se expresa con la letra E seguida de un número. Así podemos identificar algunos de los colorantes permitidos como:

- Antocianinas.

- Azul de bromotimol.

- Capsantina/capsorubina.

- Carmín (E 120; Cl 75.470; carmín de cochinilla).

- Diestearato de calcio.

- Diestearato de magnesio.

- Diestearato de zinc.

- Lactoflavina.

- Oxicloruro de bismuto. 
- Riboflavina.

- Verde de bromocresol.

- Cl 10.006 y otros 138 colorantes con código ' $\mathrm{Cl}$ ', entre ellos: amaranto $(\mathrm{Cl} 16.185)$, azul de Prusia $(\mathrm{Cl}$ 77.510), betacaroteno $(\mathrm{Cl} 40.800$ y $\mathrm{Cl} 75.130)$, cantaxantina $(\mathrm{Cl}$ 40.850), 5,5'-indigo-disulfonato de sodio ( $\mathrm{Cl} 73.015)$, dióxido de titanio (Cl 77.891), entre otros.

\section{Ingredientes alergénicos}

Entre la gran cantidad de ingredientes que potencialmente pueden formar parte de un producto cosmético, debemos tener presente aquellos que ya se han identificado como causas de reacciones alérgicas importantes en algunas personas sensibles. En los últimos años, el aumento del empleo de productos cosméticos en nuestro entorno, ha provocado que se hayan duplicado los casos de dermatitis de contacto ${ }^{7}$. En la actualidad, se estima que el $30 \%$ de las dermatitis de contacto están asociadas a la aplicación de un cosmético, mientras que hace 20 años esta cifra alcanzaba solo el $15 \%$.

Ingredientes alergénicos son el colorante carmín (o carmín de cochinilla), el bálsamo del Perú, la lanolina, parafenilendiamina (colorante), los anestésicos locales del grupo 'para' (benzocanía, tetracaína, dibucaína, etc.) usados en de- pilatorios y lociones para el bronceado. En la tabla $V$ se listan 26 ingredientes permitidos en los cosméticos como fragancias o perfumes identificados como alergénicos, que deben estar recogidos en el conjunto de ingredientes descritos en el etiquetado.

Recientemente el Consejo de Europa ha emitido una nueva resolución respecto a los tatuajes. La posibilidad de utilizar sustancias colorantes de forma permanente ha disparado las recomendaciones para evitar agentes con riesgo mutagénico y cancerígeno. En sucesivas listas de agentes colorantes, las agencias sanitarias se han hecho eco de estas propuestas. En la página de Internet de la AEMPS se puede consultar la Resolución ${ }^{8}$ citada.

\section{Denominaciones ¿orientativas 0 comerciales?}

En cierto tipo de productos cosméticos se incluyen menciones características del producto, que pueden ayudar al usuario.

\section{Cosmético sin conservantes}

Los adelantos en las condiciones de fabricación (materias primas con exhaustivos controles bacteriológicos y fabricación en zonas estériles), así como los envases utilizados (ampollas mono- 
dosis, frascos opacos y herméticos que dosifican la cantidad precisa), hacen posible que cada vez sea más frecuente preparar cosméticos que no incluyen conservantes en su composición. También es posible que alguno de los componentes de la formulación cumpla con esta función, como los aceites esenciales con acción antiséptica (canela, té), el ácido salicílico y las sustancias anticaspa. Incluso la propia formulación puede impedir el crecimiento de microorganismos, como ocurre en las lociones de alto contenido alcohólico y en los cosméticos con valores de $\mathrm{pH}$ extremos, como tintes capilares o cremas depilatorias.

\section{Cosmético hipoalergénico}

El cosmético hipoalergénico está formulado para reducir al mínimo el riesgo de alergia, aunque no significa que lo elimine totalmente. En su formulación se

Tabla V. Ingredientes alergénicos que pueden formar parte como fragancias o perfumes de los cosméticos

- 2-(4-terc-butilbencil) propionaldehído

-3-metil-4-(2,6,6-trimetil-2-ciclohexen-1-il)-3-buten-2-ona

- Alcohol 4-metoxibencílico

- Alcohol amilcinamílico

- Alcohol bencílico

- Alcohol cinamílico

- Benzoato de bencilo

- Cinamal

- Cinamal amílico

- Cinamato bencílico

- Citral

- Citronelol

- Cumarina

- Eugenol

- Evernia furfuracea, extracto

- Evernia prunastri, extracto

- Farnesol

- Geraniol

- Heptino carbonato de metilo

- a-Hexilcinamaldehído

- Hidroxicitronelal

- Hidroximetil-pentilciclohexenocarbaldehído

- Iso-eugenol

- Linalol

- d-Limoneno

- Salicilato bencílico 
han escogido ingredientes que han superado una serie de estudios de tolerancia y se han eliminado, en lo posible, los agentes más susceptibles de producir alergia, como los conservantes, los perfumes y algunos colorantes. La composición final contiene pocos ingredientes para reducir la posibilidad de encontrar nuevas sustancias desencadenantes del proceso. Los cosméticos hipoalergénicos están indicados para pieles que se irritan fácilmente, personas con piel sensible, o reactiva ante los cambios climáticos o de producto. Al respecto, conviene distinguir la diferencia entre los términos alergia e irritación. La alergia aparece cuando el cosmético ya se ha aplicado una o más veces $y$, en ocasiones, lejos de la zona de aplicación. Por ejemplo, la alergia provocada por las lacas de uñas suele afectar a los párpados y provoca picor, enrojecimiento, inflamación e incluso descamación. La irritación, en cambio, aparece inmediatamente después de la primera aplicación, en la zona tratada con el cosmético. Cuando se elimina el cosmético y se aplica un preparado calmante, desaparece la irritación.

\section{Cosmético sin perfume}

Suelen ser cosméticos destinados a zonas delicadas, como el contorno de los ojos, o a pieles reactivas. En otras ocasiones, algún extracto o aceite esencial de la fórmula realizan esta acción.

\section{Cosmético no comedogénico}

Se definen así los cosméticos cuando han demostrado que su aplicación no produce comedones en la piel. Estos productos son los únicos que se pueden aplicar en pieles acneicas y en pieles asfícticas (con tendencia a formar comedones).

\section{Cosmético oil-free}

El término oil-free ('libre de aceites') es una denominación algo confusa, pues en algunos países significa que el cosmético no contiene ni aceites ni grasas, mientras que en otros lugares se refiere únicamente a aceites. Son productos indicados para pieles grasas y acneicas. En el caso concreto de los maquillajes, son los únicos que se pueden aplicar en las pieles con acné.

\section{Testado dermatológicamente}

La frase testado dermatológicamente indica simplemente que el producto ha sido probado por dermatólogos para evaluar su eficacia sobre pacientes o sobre voluntarios. Para que los resultados del estudio sean realmente orientativos de la eficacia del cosmético y no un simple argumento de propaganda, junto a 
los resultados debería aparecer la duración del estudio, la frecuencia de aplicación y la cantidad de producto aplicada.

\section{Conclusiones}

El uso de los cosméticos debe suponer el menor riesgo para pieles sensibles o con dermatitis. Si bien la regulación normativa de este tipo de productos supone un control y unos requerimientos que aseguran el uso inocuo, es cierto que en personas con piel sensible o con dermatitis es necesario extremar el uso adecuado de los productos cosméticos, una vez comprobado en su etiquetado la ausencia de ingredientes no inocuos para el paciente individual. El conocimiento pleno de las sustancias de riesgo para ciertas personas, hace imprescindible el asesoramiento del médico especialista en terapias dermatológicas. Junto con asesorías multidisciplinares, el especialista recomendará o suprimirá ciertos cosméticos en pacientes concretos.
Cada día más, las nuevas tecnologías y el trabajo colaborativo entre diferentes profesionales de la salud permite el uso adecuado de los cosméticos, productos cuyo fin es el de limpiar, perfumar, modificar el aspecto de las superficies corporales y/o corregir los olores corporales y/o protegerlos o mantenerlos en buen estado. Todo ello sin perjudicar o empeorar la salud del paciente. En los casos en los que se identifiquen efectos adversos deben comunicarse a las administraciones sanitarias, en particular la AEMPS, para su información y, en su caso, para tomar posibles medidas reguladoras. La "cosmetovigilancia" debe implantarse9. Todo ello bajo la máxima hipocrática: primum non nocere.

\section{Nota del autor}

El contenido es responsabilidad del autor y no refleja necesariamente las opiniones de la institución donde trabaja, la Agencia Española de Medicamentos y Productos Sanitarios.

\section{Bibliografía}

1. Council of Europe, Committee of Ministers, 979th meeting of the Minister's Deputies: Resolution Res AP (2006) 1E on a vigilance system for undesirable effects of cosmetic products ("cosmetovigilance") in Europe in order to protect public health [consultado el 12/09/08]. Disponible en www.coe.int/t/dc/press/NoteRedac2006/20 061109_cosmetovigilance_en.asp

2. Real Decreto 1599/1997, de 17 de octubre, que recoge la regulación de productos cosméticos (BOE 31-10-97). Texto refundido con sus posteriores modificaciones y actualizaciones en la página de Internet de la AEMPS [consultado el 
12/09/08]. Disponible en www.agemed.es/acti vidad/legislacion/espana/docs/rcl_1997_25722008-2.pdf

3. Servicio de Información Toxicológica (SIT), Instituto Nacional de Toxicología y Ciencias Forenses, del Ministerio de Justicia [consultado el 12/09/08]. Disponible en www.mju.es/toxicolo gia/analisis/sitM.htm

4. Decisión de la Comisión Europea, 2006 /257/CEE, de 9 de febrero de 2006, que modifica la Decisión 96/335/CE, por la que se establece un inventario y una nomenclatura común de ingredientes empleados en los productos cosméticos. Disponible en la página de Internet de la AEMPS [consultado el 12/09/08]. Disponible en www.agemed.es/actividad/pschb/docs/inven tario_cosmet-junio06.pdf

5. Agencia Española de Medicamentos y Productos Sanitarios. Nota informativa sobre el producto cosmético "Mene \& Moy Yellow Peel", comercializado por Mediform Productos y Servicios Médicos, S.L. 19 junio 2008 [consultado el
12/09/08]. Disponible en www.agemed.es/acti vidad/alertas/pchb/mene-moy-junio08.htm

6. Agencia Española de Medicamentos y Productos Sanitarios. Nota informativa sobre producto "CNA CREMA" comercializado por Lou Cosmética Aplicada, 7 noviembre 2006 [consultado el 12/09/08]. Disponible en www.age med.es/actividad/alertas/pchb/CNA-crema _nov06.htm

7. Sautebin L. Understanding the Adverse Effects of Cosmetics. A pilot project in Cosmetovigilance. Drug Safety. 2008;31:433-6.

8. Consejo de Europa. Comité de Ministros, Resolución Res AP (2008) 1 sobre los requisitos y criterios de seguridad de tatuajes y maquillaje permanente (sustituye a la Resolución Res AP(2003)2 sobre tatuajes y maquillaje permanente) [consultado el 12/09/08]. Disponible en www.agemed.es/actividad/pschb/docs/resolu cionCE_tatuajes-junio08.pdf

9. Moretti U, Velo G. Cosmetovigilance. The "Beautiful" Risk. Drug Safety. 2008;31:437-9. 